\title{
The Distinctive Managerial Challenges of Hybrid Organizations: Which Skills Are Required?
}

Farah Nabil Adel Al Taji and Irene Bengo

Management, Economics and Industrial Engineering Department, Politecnico di Milano, Milan, Italy

\begin{abstract}
How do the distinctive managerial challenges of hybrid organizations look appear in practice? Which skills can be taught to respond to those challenges? These important questions are investigated based on, first, an in-depth study of social incubators/accelerators and social ventures (SVs). Second, building upon the "paradoxical leadership model for social entrepreneurs" (Smith et al. 2012), the study associates the specific challenges in practice with the model's specific skills. This study has value not only for the social entrepreneurship (SE) literature but also for SE educators, social incubators/accelerators and social entrepreneurs who are all engaged in the capacity building of SVs.
\end{abstract}

\section{KEYWORDS}

Hybrid organizations; social ventures; social entrepreneurship education; human resources; capacity building

\section{Introduction}

Over the last decade, the phenomenon of social entrepreneurship (SE) has experienced impressive growth, where it has "gained momentum and the communities around the world are self-organizing to directly address issues that affect them” (Ayob et al. 2013). 
Agoston (2014) claimed that failures in the system, market, government, volunteer sector and others drive the emergence and growth of this phenomenon. Thus, establishing SVs has become a trend in a wide range of fields and sectors, such as education, healthcare, poverty, inequality, unemployment, migration and other societal challenges (Battilana et al. 2012).

SV has a variety of definitions, but two main features are commonly mentioned in a majority of them: a social venture seeks to meet a social need, and it performs entrepreneurial activities to generate a profit to maintain/scale the generated social impact (Tracey and Phillips 2007; Bengo et al. 2016).

Moreover, the growth in interest in SVs is attributed to social, economic and political trends. Those trends have required SVs to pursue a social value that is the core and main driver, while SVs have the role of managing commercial activities to achieve a financial value that has, in turn, the role of sustaining a social impact and decreasing reliance on donations (Doherty, Haugh, and Lyon 2014; Arena et al. 2018). This indicates that the social and commercial missions have both been set as main values and logics of the SV organization, which has led SVs to be characterized by hybridity (Haugh 2007). The hybrid organization refers to organizations with two or more competing logics, conflicting demands or multiple pressures (Pache and Santos 2010). SVs have the classic form of a hybrid organization (Doherty, Haugh, and Lyon 2014).

Doherty et al. (2014) have reported that the main managerial challenges of hybrid SVs, based on the framework developed by Austin et al. (2006), fall into three management categories: organizational mission, financial resources, and human resources. Those aspects have gained attention because they exhibit the challenges that most distinguish SVs with two institutional logics from commercial enterprises (SimónMoya, Revuelto-Taboada, and Ribeiro-Soriano 2012). This study addresses the 
managerial area of SVs, particularly the specific distinctive challenges in managing those three dimensions and the associated skills needed to effectively manage hybrid organizations. The reason that this study is concerned with understanding the specific challenges and their associated specific skills is because the need for employees equipped with the necessary competencies to manage the distinctive challenges of hybrid organizations is increasing; however, there is currently a lack of such employees in this growing and changing market (Battilana et al. 2012; Napathorn 2018).

Every organization aims to stay focused on its mission, which is generally challenging, but in regard to hybrid organizations, with two missions (social and commercial), the task is even more challenging (Napathorn 2018; Bruneel et al. 2016; Tracey and Phillips 2007; Pache and Chowdhury 2012). The passion and commitment of the social entrepreneur (the founder/s) can help the organization to stay focused initially, but when the organization grows, it requires the founder/s, along with employees, to be able to effectively maintain the two missions.

Thus, one of the major issues stressed in the literature responding to this demand is that hiring and selection criteria as well as the development and management of internal human capital are instrumental (Battilana et al. 2012; Bruneel et al. 2016). Since there is a lack of employees with prior experience in hybrid organizations, there are three possible selection options: First, employ people with a background in either one of the sectors (nonprofit or for profit). This strategy avoids any conflict, but it probably leads to mission drift (Battilana et al. 2012). Second, employ a mix of employees from both sectors (social and commercial), but this approach could result in fighting and conflict between the two groups (Bruneel et al. 2016). Third, employ people with no prior experience in any of the sectors (fresh graduates), and then hold training and professional development sessions for them about how to maintain the balance (Battilana et al. 2012). However, this third 
criterion requires time and finances, which are limited in the SV case. In conclusion, this issue of lacking employees with prior knowledge and experience in managing hybrid organizations not only creates a shortage of human resources but also creates a dilemma in the selection criterion at SVs.

However, one possible solution to this issue is to teach students in management and business schools about hybrid organizations and equip them with the required competencies to manage such organizations with two competing demands. A study on the evolution of SE education in business and management schools showed that the interest in such schools to offer SE education significantly increased in 2014-2015 compared to 2004-2005 (Spais and Beheshti 2016). This consideration in academia has been given a prominent role by leading universities, such as Harvard, Duke, Stanford and Oxford Universities on both sides of academia: education and research (Simón-Moya, Revuelto-Taboada, and Ribeiro-Soriano 2012). Since then, many other universities have started to open streamlined SE programmes. Such education focuses on "plans, tools, theories/ theoretical models and the business-related concepts” (Spais and Beheshti 2016).

Moreover, when Plaskoff (2012) interviewed Sarah Harris, the vice president of Emmis Communications’ Incite entity who “has grown a US\$7.5 million social enterprise employing 10 social entrepreneurs” (Plaskoff 2012), Harris strongly advised business schools to equip future managers by including an SE curriculum; this advice results from the lack of business managers' awareness and knowledge about SE and social innovation (SI) that Harris has noticed. However, how can business and management schools respond to this call, considering that the hybridity of SVs adds an extra layer of complexity? (Tracey and Phillips 2007). 
Pache and Chowdhury (2012) stressed that SE education is still new and "suffers from a lack of clear theorizing”. Thus, a limited number of theoretical models about how to teach or conduct training for SE have been developed and published in academic journals; some of these have focused on the hybridity issue (i.e. Smith et al. 2012; Kickul et al. 2012; Pache \& Chowdhury 2012). However, the model developed by Smith et al. (2012), which is called the "paradoxical leadership model for social entrepreneurs", strictly connects the demand side with the supply side. The demand side is demonstrated by including two main challenges of managing organizations with two institutional logics, while the supply side is articulated by suggesting meta- and specific skills as well as pedagogical tools to teach those specific skills that are associated, with clear links, to the two main challenges. However, this study argues that the two main challenges included in Smith et al.'s (2012) model are still very general and do not clearly articulate the complex challenges of SVs. What is missing is specific practical challenges demonstrating how the general challenges appear in practice and then how specific skills can be associated with them.

Building upon the work of Smith et al. (2012), this paper aims, first, to understand the demand side by investigating, empirically, how specific managerial challenges that emerge when working at SVs appear? The second aim is to employ the specific skills and pedagogical tools suggested by the "paradoxical leadership model for social entrepreneurs” (Smith et al. 2012) to respond to those specific managerial challenges.

To answer the two aims described above, the remainder of the paper is organized as follows. First, the theoretical framework is introduced, which is based on the model proposed by Smith et al. (2012). Second, the research methods are outlined, clarifying the criteria used for selecting the sample and collecting and analysing data. Third, the results 
of this research are presented. Finally, theoretical and practical implications are discussed in the discussion and conclusion sections.

\section{Theoretical framework}

The theoretical framework of this study is based on Smith et al.'s (2012) theoretical perspective of the paradox theory (Lewis 2000), which provides astuteness about the source, nature, challenges and responses of competing demands in organizations. For an overview of the paradox theory literature, see (Smith and Lewis 2011; Smith and Tracey 2016).

Smith et al. (2012) were among the first to build a theory about the challenges and correlated skills to appropriately manage the tensions elicited from the demands of competing logics (social and commercial) at hybrid SVs; they also suggested pedagogical tools for teaching these skills. Their theoretical model, which is called "a paradoxical leadership model for social entrepreneurs”, is inspired by the award-winning undergraduate course at Cornell University (SEIP); this course demonstrates teaching SE in a classroom setting. The main argument of the work of Smith et al. (2012) is that "social and commercial sides of a social enterprise are not isolated from one another. Rather, they are inherently interrelated and often conflicting”, and that is why managing social and commercial demands require a different set of skills than those required in a traditional enterprise (Tracey and Phillips 2007; Smith et al. 2012; Pache and Chowdhury 2012; Miller, Wesley, and Williams 2012; Plaskoff 2012)

The framework of Smith et al. (2012), interestingly, connects the demand and supply sides, and it is structured in three main stages: first, identify the main managerial challenges when managing social and commercial demands. In other words, the challenges faced in managing hybrid organizations demand certain skills and 
competencies to be managed well. Second, it identifies correlated skills to embrace such challenges; this stage is divided into two sub-parts: meta-skills and specific skills. The third stage of the framework is the pedagogical tools suggested to help teach the specific skills identified in the second stage. The second and third stages illustrate the skills and pedagogical tools for future managers who can effectively manage the challenges stated in the first stage. As shown in figure 1, the connection that this model tries to create between the demand and supply sides is unique among other developed models for teaching SE (i.e. Kickul et al. 2012; Miller et al. 2012; Pache \& Chowdhury 2012; Mehta et al. 2016).

[Figure 1 near here]

Smith et al. (2012) stated in the model that there are two main challenges in managing an organization with competing social and commercial demands: The first challenge is in "maintaining both a social mission and commercial viability". The second challenge is in "overcoming intractable conflict". The argument here is that those two challenges are still very general, practically speaking; they are not concrete enough for students to understand their implications in practice. For instance, how do those challenges appear? What does it take to maintain a social mission in practice? What obstacles appear while working toward a social mission? What would limit maintaining financial viability? How would both social and financial missions be in conflict? The answers to those questions would advance the understanding of how the challenges of managing hybridity at SVs, practically, appear. Then, connecting them with the correlated specific skills and pedagogical tools is expected to allow the model to be more effective for learning and training purposes. 
The three meta-skills suggested by the model are acceptance, differentiation and integration. Those meta-skills were broken down into six specific skills that are intended to embrace the challenges in transforming the tension between the two competing demands into a source of new opportunities and solutions for the organization. Metaskills and the six specific skills are explained in greater detail later in the results section.

\section{Methods}

To study the distinctive challenges in managing SVs with a hybrid nature, the research adopted an in-depth study of Italian social incubators/accelerators and Italian SVs. Data were collected from multiple sources to capture key dimensions of the problems analysed (Yin 1994): in-depth interviews, websites and direct observations. The analysis was conducted with managers of social incubators and accelerators in Italy as well as with a number of founders of Italian SVs. With regard to the data collected through the social incubators/accelerators, the primary source of data was in-depth interviews (Goldman and McDonald 1987) with the managers of incubators and accelerators in particular. The interviewees were selected based on their ownership of responsibility for the incubation and acceleration programmes in addition to their role in following up on the progress of the incubated/accelerated SVs. While the primary source of data collected with respect to the SVs was in-depth interviews with the founder/s of each SV, the interviewees were selected based on their main role of establishing and then managing their SVs since the birth of the idea.

Social incubators and accelerators were selected for interviews not only because of their direct connection with many SVs but also because of their "profound impact on social entrepreneurship practice by identifying and supporting innovative social entrepreneurs through training, mentoring and other means” (Pandey et al. 2017). Thus, 
their managers' points of view about how the managerial challenges at SVs appear is of high value, as they are outsiders to the ventures and directly support the ventures' teams.

Three main social incubators/accelerators are selected in Italy: Impact Hub Milano, SocialFare and Make a Cube ${ }^{3}$. These incubators/accelerators were identified after a preliminary analysis of their websites and other public sources aimed at selecting incubators and accelerators that work with a variety of SVs and support them, especially with reference to their hybrid nature.

Furthermore, other criteria that drove the selection of six SVs were based on two factors: SVs that had the chance to be incubated/accelerated at one of the selected social incubators/ accelerators and SVs that did not have the chance to be incubated at a social incubator or accelerator. These ventures were identified after a preliminary analysis of their websites as well as a discussion with the managers of the incubators/accelerators aimed at selecting SVs with hybrid natures, at different stages and in various sectors.

The following two tables (Table 1 and Table 2) show the selected organizations and their main characteristics.

[Table 1 near here]

[Table 2 near here]

Overall, nine interviews were conducted. Furthermore, this study had the opportunity to enrich the data collected with follow-up and informal discussions with the above informants. Each interview lasted between 60 and 120 minutes. All the interviews were conducted one-on-one, face-to-face except for one interview via Skype, and all the interviews were conducted in Italy. Each interview was voice recorded and transcribed.

To analyse the data, a thematic analysis (Teddlie and Tashakkori 2009) was applied. This is one of the most commonly used analyses in qualitative research, and it is 
a technique used to pinpoint and record patterns or themes within data. After transcribing the interviews, approximately 100 single-spaced pages of material were produced from the three incubators/accelerators and six SVs. The produced material was then coded and summarized based on the thematic analysis. Finally, the themes were placed side by side with previous literature to validate the analysis. The in-depth study with incubators/accelerators covers the history of each incubator/accelerator, their incubation/acceleration programmes and their perspective on the learning process and challenges that face SVs during their growth. The in-depth study with the SVs covers the history of each SV, the challenges they faced during their journeys and the learning process each SV has experienced.

\section{Results}

This section demonstrates the results in two parts: first, the specific challenges of managing competing demands at SVs and how those challenged appear in practice and, second, the association of those specific challenges with the specific skills and pedagogical tools suggested by Smith et al. (2012) in their model “a paradoxical leadership model for social entrepreneurs”.

\section{Specific challenges to manage SVs with competing demands}

Data from the interviews elicited four themes of challenges that are distinctive for SVs with competing demands. These were the risk of mission drift, the need for impact measurement, stakeholders' conflicting demands and SVs based on new technologies. Each one of these challenges has different implications under the three managerial dimensions defined by Austen et al. (2006): organization mission, financial resources, and human resources. Table 3 shows how each of the elicited challenges appears within those three managerial dimensions. 


\section{Organizational mission}

Two main tensions are expected to appear when talking about the organizational mission of a hybrid organization: risk of mission drift and stakeholders' conflicting demands (Doherty, Haugh, and Lyon 2014; Pache and Chowdhury 2012). Both managers of incubators/accelerators and founders of SVs stressed the point that it is challenging is to stay focused on the main missions (social and financial) and be able to communicate the organizational mission strongly. According to the manager of the SocialFare accelerator,

Launching a venture is really tough; if you are social, it's probably even tougher, as you have to stay true to your mission and vision, so you ae aware of this mission drift problem...This can come at the expense of the social value of the project; it never happened to us but it's always a balancing and trade-off between these two values, although all of the start-ups that we accelerated had very clear and strong social visions and social vocations.

Additionally, because of the nature of such ventures, they are multi-stakeholder organizations, where stakeholders have different demands, which, in turn, creates challenges about on how to communicate with each stakeholder. As the co-founder of Merits stated,

We often said that to start talking is similar to a teenager who is defining their identity, so an important part of that is the work that we are doing now with service designers, and it is about really defining our identity and the identity of our stakeholders, how and why they interact with us... You know that if you meet a business, you have to speak a certain language; if you meet the 3rd sector benefits association, you have to speak another language; if you meet small entrepreneurs who want to help you, you have to speak a different language than if you meet a big corporation. 
In particular, The results demonstrate the third challenge that is relevant to SVs based on new technologies, such as blockchains. For example, the lack of knowledge about blockchain technology creates a perception that it is an evil technology, and this, of course, contradicts the use of such technology to create social impacts, which, in turn, creates an extra layer of complexity for social entrepreneurs when defining their SV identity. The co-founder of Helperbit elaborated on this point:

The main challenge, in my opinion, is the lack of trust in Bitcoin and Blockchain because many people read news about the coin and they think the coin is illegal, is evil, and is used only by the Mafia ... but obviously, it is not, and we are the best example for this because Bitcoin and blockchains are just technology, are just tools... it is quite complex, and we have to help NGOs to understand the technology... NGOs are quite scared by this at the moment.

\section{Financial resources}

Social entrepreneurs face difficulties in raising capital mainly because capital investors are not comfortable with hybrid organizations as an investment, but impact investors are more comfortable with those organizations (Battilana et, al. 2012). However, impact investment is still an emerging field, which is why the managers of incubators/accelerators, as well as the founders of SVs, raised this point as a challenge. The manager of Impact Hub Milano said

Some people have very interesting business models in the environmental or social arenas... I heard investors say "but you are not social because you make a profit, or you make a great deal of money, too much money"... for example, there is a startup here called job network; it's a marketplace to match people with disabilities, physical disabilities, with a job in Italy or around the world ...because they make money through the company for these kinds of people like a normal head-hunter ...I heard people that say but how do you calculate the impact and ...I remember the 
answer of the investor who is a venture capitalist said no ... in fact, now I would like to talk more about impact investing and not more about social innovation because, in Italy, when you say social innovation, it is philanthropy, clerical, with no profit. Moreover, it is not only difficult to obtain the support of investors for SVs that make money in addition to having a social impact but also to obtain the support of public institutions. According to the founder of Sport Grand Tour,

Like schools and municipalities and so on, they don't want to work with for profit companies because they say we cannot promote one company and not the other. In my opinion, it’s okay, this approach is okay, but if you recognize from a legal point of view the social impact, because we are innovative start-up with a social impact, so if you recognize this because you made the law and incentives in order to invest in social impacts because you think social impact is important so your institution must recognize this.

In addition to the issue of external stakeholders' misconceptions about SVs, another two challenges have been raised with regard to financial resources, which are the risk of mission drift and the need for impact measurement, as shown in Table 3. However, the risk of mission drift occurs because social entrepreneurs have to be focused on market needs in addition to social needs, and in many cases, they are not the same (Alberti and Varon Garrido 2017). On the other hand, impact measurement is continuously a demand of investors, governments and other stakeholders. However, there are no standard measures for social impacts, and the cost of such measurements are stressed as distinctive challenges for SVs in the interviews. According to an interview with the manager of Make a Cube ${ }^{3}$ incubator,

There should be a standard methodology to measure it, so standard communicators... you have to balance this trade-off between reliability, in terms of scientific 
measurement, and the cost and time that an entrepreneur is going to spend on that topic.

With respect to new technologies, the co-founder of Helperbit talked about how using new technology such as blockchain adds a third dimension to the fundraising discussion:

It depends on who is the investor because we are talking with banks and insurance companies. For example, banks are not into the insurance part and only want to be involved in the humanitarian part from the technology point of view and the visibility point of view, so they want social impact, while, for example, insurance companies want the technology aspect and the insurance service, while, regarding the social part, they don't care about it. If this process includes banks and insurance companies, it is then very long, very complex ... because they prefer a mature technology.

\section{Human Resources}

SVs with dual missions require workers from different backgrounds and with different interests to meet the needs of both missions (Dufays and Huybrechts 2016). The results show that human resource issues are relevant to the four challenges: risk of mission drift, impact measurement, managing multi-stakeholders' demands and technology. For instance, when people who work at SVs (i.e., founders, employees, volunteers) are not competent enough about what an organization with competing demands is, this raises the risk of mission drift as well as the possibility of creating an internal conflict between people with a social orientation and people with a business focus. The manager of Make a Cube ${ }^{3}$ incubator opined that

Usually, when talking about the challenges and the barriers in the ecosystem, we always need more investors, and that's a part of the supply side. However, we also need much more maturity on the demand side; I feel that it's the most important need of all. I think that once we are able to demonstrate the talented people working on 
social issues and finding a sustainable, not a scalable and profitable business model, but a sustainable business model, money will come.

The manager of the Make a Cube3 incubator elaborated more on the conflict that might occur between internal stakeholders, such as workers who come from a social background and others who come from the business background.

When we talk about targeting the market, for example, they (people coming from the $3^{\text {rd }}$ sector) say "I have worked with these people for 15 years, I know them perfectly," and yes, you know one part, you know your beneficiaries, but your beneficiary is not always your customer, so you have to focus on which is the perceiving process of your position according to your customer, not only according to your beneficiary, and this... talking to people coming from the for profit sector, the big challenge is that they lack the deep knowledge of the social issue they are going to tackle, and it's not so easy in the beneficiary issues and not just in the customer issues... in general, something that is really important in vocal terms is also to understand that in the social sector you have to develop experiments in order to understand the potential of your idea, and you want validate the process

The challenge of impact measurement with respect to human resources is two-fold: (1) the need for competences capable of providing reliable and effective impact measurements and (2) the need for people who can communicate the created social impact by the SV. On the other hand, the challenge of SVs based on new technology requires competences to convince different stakeholders about the capability of the new technology to generate a social impact.

[Table 3 near here]

\section{Synthetic analysis}

Figure 2 shows a synthetic analysis of the specific challenges identified from the results of the interviews. Figure 2 illustrates how the three managerial aspects (organizational mission, financial resources, human resources) are each connected with the four specific 
challenges (risk of mission drift, the need for impact measurement, stakeholders' conflicting demands, SVs based on new technology); furthermore, the figure provides a description of each specific challenge.

[Figure 2 near here]

\section{Association of the specific challenges with the specific skills and pedagogical} tools suggested by Smith et al. (2012)

The second part of the results connects the four specific challenges extracted in the first part of the results with the six specific skills suggested by Smith et al.'s (2012) model, as shown in Table 4.

[Table 4 near here]

Based on the model of Smith et al. (2012), the definitions of the three meta-skills and suggested six specific skills with the pedagogical tools to teach them in a classroom setting are as follows. Additionally, an explanation of how Table 4 has been developed to integrate the specific challenges in practice with the skills of the model are as follows. Acceptance

This "involves viewing both sides of competing demands as simultaneously possible, even if they are inherently in conflict” (Smith et al. 2012). In other words, the acceptance of both missions at hybrid organizations, in this case the social and commercial missions at SVs, would influence the commitment to each mission and open minds to recognize such competing demands as a blessing but not a burden. Two specific skills have been suggested in correlation with acceptance. 
Adopting an abundance mentality: This specific skill helps managers at SVs to accept both competing demands by thinking of a problem as an opportunity, building community and opening dialogue to look for possibilities rather than limitations and difficulties. This skill can be enhanced in a classroom setting by enabling students to share ideas, learn from one another, support each other while completing a certain task, in other words, to collaborate rather than compete with each other. This can also be achieved through grading strategies if they are based on collaboration instead of competition. Further, this can be achieved by assigning exercises about how to provide constructive feedback to one another and to oneself as well as exercises to stimulate thinking of as many positive things as they can about a given scenario. In Table 4, associating this specific skill with the two specific challenges, risk of mission drift and stakeholders' conflicting demands, has been suggested. An abundance mentality can help managers avoid mission drift by being able to accept both social and commercial demands, which, in turn, help managers focus on each demand. Furthermore, accepting both demands is sufficient to open the space for building communities from both sides, which is essential to decrease the risk of mission drift. On the other hand, managing stakeholders' conflicting demands requires an abundance mentality to open minds to accept diversity in stakeholders' methods of thinking and their demands.

Embracing paradoxical thinking: This is the ability to recognize competing demands on each side. When two different actors have not only different but competing demands, then decisions are most likely made based on the "either/or" strategy. Paradoxical thinking allows managers to first recognize both demands and then accept them, which leads to making decisions based on a different strategy, "both/and". This skill can be taught to students in a classroom setting by exposing them to scenarios, through readings or role playing, in which two different actors are in the same situation but have different and 
competing demands. In Table 4, associating this specific skill with the two specific challenges, risk of mission drift and stakeholders' conflicting demands, has been suggested. Recognizing the conflicting demands of different sides (social and commercial) or different actors (volunteers and employees or beneficiaries and clients) has a vital role in avoiding mission drift and managing stakeholders’ competing demands.

\section{Differentiation}

This refers to being able to differentiate the characteristics of each side of competing demands, including each side's added value, which is the step after acceptance and feeling more committed to both sides; differentiation will take managers a step further toward maintaining their commitment to each side. In this case, that is their commitment to social and commercial demands. Two specific skills have been suggested by Smith et al. (2012) to encourage differentiation.

Recognizing the Distinct Value of Each Domain: To recognize the distinct elements of each domain, the capability to develop and measure each mission separately from the other is crucial. Teaching students in the classroom to develop a business plan and measure social impact, for example, would influence their ability to distinguish the value of each domain. Furthermore, giving students the opportunity to develop an idea for a SV and build its business model and plan on how to generate its social value is another possible way of learning differentiation. In Table 4, associating this specific skill with the two specific challenges, risk of mission drift and the need for impact measurement, has been suggested. Because recognizing the distinct value of each domain is about giving students (future managers of SV) tools for measuring social impacts and developing a business plan that, in turn, allows them to stay focused on market needs and value creation and provides them with measures, so this value can be communicated later to mobilize resources. 
Mindfully Attending to Distinctions Between Domains: This specific skill is more about "the ability to seek out novel information about the domains, which in turn enables leaders to make nuanced distinctions between the domains” (Smith et al. 2012). To teach students in the classroom on how to seek novel information about each domain, training about divergent thinking, as one example, can be facilitated. This means asking students to think of alternatives to one problem or question rather than providing only one solution. In Table 4, associating this specific skill with the two specific challenges, stakeholders' conflicting demands and SVs based on new technology, has been suggested. The capability of thinking of many alternative solutions to one aspect or problem can help managers find different ways of communicating complexity, such as the complexity of new technology. Additionally, to be able to recognize specific distinctions between the demands of different stakeholders (investors and government) would probably help managers to think of a variety of solutions for how to deal with the demands they face.

\section{Integration}

This refers to the ability to integrate both sides of conflicting demands constructively rather than destructively. Integration is a third step after maintaining commitment through differentiation to help managers and creating "synergies between contradictory elements" (Smith et al. 2012). Two specific skills have been correlated with integration.

Developing Trust, Openness, and Cultural Sensitivity: The skill of creating a safe space characterized by openness, trust and cultural sensitivity and including actors who are strongly committed to the different sides (social and commercial) would allow for an open environment to exchange ideas and opinions. Such environments are a fruitful space for managers to understand complexity and find new methods of integration. This skill can be taught in a classroom setting through field projects by giving students the opportunity to go outside the classroom and work with real SVs. Furthermore, teachers 
can create groups of students with a safe space for all group members to exchange personal perspectives and goals. Such groups without judgemental mindsets are sufficient to train students about being accepting of diversity and open to other cultures. In Table 4, associating this specific skill with the three specific challenges, risk of mission drift, stakeholders' conflicting demands and SVs based on new technology, has been suggested. The main reason for this association is that developing trust, openness and cultural sensitivity is important for creating a community and open communication between internal stakeholders (i.e., founders, employees and volunteers) as well as with external stakeholders (i.e., investors, other SVs, beneficiaries, clients and public sector), which, in turn, is expected to lead to finding new methods of mutual understanding and the integration of ideas.

Seeking Synergies in Decision Making: This is the ability to make decisions while making sure that both sides of competing demands are supported. This competence can be taught to students by developing their idea for creating an SV, the one they developed for differentiation, but this time, their thinking is stimulated to show how the success of their idea is based on the integration between social and business demands. In addition, in the classroom, inviting social entrepreneurs as role models to tell stories about decisions they have made successfully while supporting both sides (social and commercial) would help students learn integration. In Table 4, associating this specific skill with the three specific challenges, risk of mission drift, the need for impact measurement and stakeholders' conflicting demands, has been suggested. This association is considered because the skill of decision making is important to avoid mission drift, use conflict as an opportunity rather than a burden and help balance different domains and needs. 


\section{Discussion and conclusion}

The paper contributes to the social entrepreneurship literature by adding to the debate regarding the distinctive managerial challenges of hybrid organizations (Simón-Moya et al. 2012). Those distinctive challenges call for different managerial competencies than those needed for traditional ventures (Battilana et al. 2012). However, SE education, which is expected to contribute to the capacity building of SVs as hybrid organizations (Kickul, Janssen-Selvadurai, and Griffiths 2012),“ suffers from a lack of clear theorizing” (Pache and Chowdhury 2012).

The empirical analysis of this study is framed by the model proposed by Smith et al. (2012). Based on this framework, the paper analyses how a better understanding of how the distinctive specific challenges appear in practice; accordingly, the model suggested by Smith et al. (2012) has been extended. The model is extended by, first, correlating the investigated distinctive specific challenges with the three managerial dimensions defined by Austen et al. (2006) (organization mission, financial resources, human resources). Second, those specific challenges are associated with the model's specific skills and pedagogical tools. An an outcome of this paper, this extended model contributes to the theorizing of SE education and is expected to have implications for SE education, where educators in the field can benefit from it to improve their SE training and teaching materials. This research is important because social entrepreneurs, social incubators/accelerators and educators in the field are increasingly engaged in a capacitybuilding efforts to further advance the capability of SVs' human capital.

Four distinctive specific challenges are elicited in this paper: risk of mission drift, the need for impact measurement, stakeholders' confecting demands and SVs based on new technology. However, an unexpected result is the challenge of SVs based on new technology. The results show that a new technology, such as blockchain, adds a third 
dimension in addition to the other two dimensions (social and commercial). This might open an interesting venue for future research about how new technology, such as blockchain technology, might add an extra layer of complexity when managing SVs with hybrid natures. In addition, there is the question of whether there are distinct challenges when managing such SVs. However, few studies have addressed SVs based on new technology (i.e. Ismail, Hossain, and Nor 2012; Arena et al. 2018). The other three challenges elicited in this paper are consistent with the literature (Tracey and Phillips 2007; Doherty, Haugh, and Lyon 2014). This paper shows how all of these specific challenges look appear in practice and what it takes to effectively embrace each of those challenges.

Thinking and communication skills with internal and external stakeholders illustrate the most important skills, whereas the suggested specific skills in Smith et al.'s (2012) model strongly focus on soft skills, thinking abilities and fieldwork, which are highly required in managing SVs with hybrid natures. However, two points for further improvement are suggested as follows: First, allow for more experimental learning (Pache and Chowdhury 2012; Chang, Benamraoui, and Rieple 2014; Tracey and Phillips 2007) to enhance communication skills with different actors in the SE system. This can be applied, for example, by exposing students their expected beneficiaries and clients while working on the big idea project.

Second, strengthen the model with a stronger theoretical basis in addition to the suggested specific skills. However, the interaction between individuals, field (practice) and domain (theories) are argued to provide a sufficient learning experience and to encourage creativity (Csikszentmihalyi 1999). The extended model suggested by this paper, by adding the specific challenges correlated with the three managerial aspects, provides a foundation for how to correlate theories with the model to further enhance 
students' knowledge of hybrid organizations (i.e., theory of change, SVs scaling strategies, typologies of hybrid organizations, and the stakeholder theory). This invites further reflection about how to extend the model with theories.

This study is limited in its ability to generalize the results of the specific challenges because it was based on a limited number of SVs and incubators/accelerators. Therefore, future research should test the four specific challenges with a larger sample of SVs and social incubators/accelerators using a quantitative approach to create opportunities for generalizability, particularly with regard to what has been noted about SVs based on new technology.

Moreover, future research should test the model by conducting an experiment on a sample of students by developing measures for each specific skill to measure the effectiveness of the model in a classroom setting. On the other hand, the model could be used to evaluate the gaps in any SE educational programme.

\section{Disclosure statement}

No potential conflict of interest was reported by the author. 


\section{References}

Alberti, Fernando G., and Mario A. Varon Garrido. 2017. “Can Profit and Sustainability Goals Co-Exist? New Business Models for Hybrid Firms." Journal of Business Strategy 38 (1): 3-13. doi:10.1108/JBS-12-2015-0124.

Arena, Marika, Irene Bengo, Mario Calderini, and Veronica Chiodo. 2018. "Unlocking Fi Nance for Social Tech Start-Ups : Is There a New Opportunity Space ?" Technological Forecasting \& Social Change 127 (June 2017): 154-65. doi:10.1016/j.techfore.2017.05.035.

Ayob, Noorseha, Ching Seng Yap, Dewi Amat Sapuan, and Md Zabid Abdul Rashid. 2013. "Social Entrepreneurial Intention among Business Undergraduates: An Emerging Economy Perspective." Gadjah Mada International Journal of Business 15 (3): 249-67. http://www.scopus.com/inward/record.url?eid=2-s2.084890187035\&partnerID=tZOtx3y1.

Battilana, By Julie, Matthew Lee, John Walker, and Cheryl Dorsey. 2012. "In Search of the Hybrid Ideal." Stanford Social Innovation Review.

Bengo, Irene, Marika Arena, Giovanni Azzone, and Mario Calderini. 2016. “Indicators and Metrics for Social Business: A Review of Current Approaches." Journal of Social Entrepreneurship 7 (1): 1-24. doi:10.1080/19420676.2015.1049286.

Bruneel, Johan, Nathalie Moray, Robin Stevens, and Yves Fassin. 2016. "Balancing Competing Logics in For-Profit Social Enterprises: A Need for Hybrid Governance." Journal of Social Entrepreneurship 7 (3). Taylor \& Francis: 263-88. doi:10.1080/19420676.2016.1166147.

Chang, Jane Yann Ching, Abdelhafid Benamraoui, and Alison Rieple. 2014. "Stimulating Learning about Social Entrepreneurship through Income Generation Projects." 
International Journal of Entrepreneurial Behaviour \& Research 20 (5): 417-37. doi:http://dx.doi.org/10.1108/09564230910978511.

Csikszentmihalyi, Mihaly. 1999. "Implications of a Systems Perspective for the Study of Creativity." In Handbook of Creativity, 313-35. N ew York: Cambridge University Press.

Doherty, Bob, Helen Haugh, and Fergus Lyon. 2014. "Social Enterprises as Hybrid Organizations: A Review and Research Agenda." International Journal of Management Reviews 16 (4): 417-36. doi:10.1111/ijmr.12028.

Dufays, Frédéric, and Benjamin Huybrechts. 2016. "Where Do Hybrids Come from? Entrepreneurial Team Heterogeneity as an Avenue for the Emergence of Hybrid Organizations." International Small Business Journal 34 (6): 777-96. doi:10.1177/0266242615585152.

Goldman, Alfred E., and Susan Schwartz McDonald. 1987. The Group Depth Interview: Principles and Practice. Prentice Hall.

Haugh, Helen. 2007. "Community- Led Social Venture Creation." Entrepreneurship: Theory and Practice 31 (2): 161-82. doi:10.1111/j.1540-6520.2007.00168.x. Ismail, Kamariah, Mir Hossain, and Umee Nor. 2012. "Technology Social Venture : A New Genré of Social Entrepreneurship ?" Procedia - Social and Behavioral Sciences 40. Elsevier B.V.: 429-34. doi:10.1016/j.sbspro.2012.03.211.

Kickul, Jill, Christine Janssen-Selvadurai, and Mark D. Griffiths. 2012. “A Blended Value Framework for Educating the Next Cadre of Social Entrepreneurs." Academy of Management Learning \& Education 11 (3): 479-93. doi:10.5465/amle.2011.0018. Lewis, Marianne W. 2000. “Exploring Paradox : Toward a More Comprehensive Guide Author ( s ): Marianne W. Lewis Source: The Academy of Management Review, 
Vol . 25, No . 4 ( Oct ., 2000 ), Pp . 760-776 Published by : Academy of Management Stable URL : Http://Www.Jstor.Org/Stabl." Academy of Management Review 25 (4): 760-76.

Miller, Toyah L, Curtis L Wesley, and Denise E Williams. 2012. “Educating the Minds of Caring Hearts: Comparing the Views of Practitioners and Educators on the Importance of Social Entrepreneurship Competencies." Academy of Management Learning \& Education 11 (3): 349-70. doi:10.5465/amle.2011.0017.

Napathorn, Chaturong. 2018. "Which HR Bundles Are Utilized in Social Enterprises? The Case of Social Enterprises in Thailand." Journal of Social Entrepreneurship 9 (2). Taylor \& Francis: 110-31. doi:10.1080/19420676.2018.1452282.

Pache, Anne-Claire, and Imran Chowdhury. 2012. "Social Entrepreneurs as Institutionally Embedded Entrepreneurs: Toward a New Model of Social Entrepreneurship Education." Academy of Management Learning \& Education 11 (3): 494-510. doi:10.5465/amle.2011.0019.

Pache, Anne-Claire, and Filipe Santos. 2010. "When Worlds Collide : The Internal Dynamics of Organizational Responses." Academy of Management Journal 35 (3): 455-76. doi:10.5465/AMR.2010.<strong>51142368</strong>.

Pandey, Sheela, Saurabh Lall, Sanjay K. Pandey, and Sucheta Ahlawat. 2017. "The Appeal of Social Accelerators: What Do Social Entrepreneurs Value?" Journal of Social Entrepreneurship 8 (1). Taylor \& Francis: 88-109. doi:10.1080/19420676.2017.1299035.

Plaskoff, Josh. 2012. "Building the Heart and the Mind: An Interview with Leading Social Entrepreneur Sarah Harris." Academy of Management Learning and Education 11 (3): 432-41. doi:10.5465/amle.2011.0010. 
Simón-Moya, Virginia, Lorenzo Revuelto-Taboada, and Domingo Ribeiro-Soriano. 2012. "Are Success and Survival Factors the Same for Social and Business Ventures?" Service Business 6 (2): 219-42. doi:10.1007/s11628-012-0133-2.

Smith, Wendy K, Marya L Besharov, Anke K Wessels, and Michael Chertok. 2012. “A Paradoxical Model for Social Entrepreneurs: Leadership Skills and Pedagological Tools for Managing Social and Commerical Demands." Academy of Management Learning \& Education 11 (3): 463-78.

Smith, Wendy K, and Marianne W Lewis. 2011. "Toward a Theory of Paradox: A Dynamic Equilibrium Model of Organizing." Academy of Management Review 36 (2): 381-403. doi:10.5465/amr.2009.0223.

Smith, Wendy K, and Paul Tracey. 2016. "Institutional Complexity and Paradox Theory: Complementarities of Competing Demands." Strategic Organization 14 (4): 45566. doi:10.1177/1476127016638565.

Spais, George S, and Hooshang Beheshti. 2016. "The Evolution of Social Marketing and Social Entrepreneurship Education in Business and Management Schools: Conceptions, Misconceptions and Trends." European Journal of International Management 10 (4): 422-54. doi:10.1504/EJIM.2016.077423.

Teddlie, Charles, and Abbas Tashakkori. 2009. Foundations of Mixed Methods Research: Integrating Quantitative and Qualitative Approaches in the Social and Behavioral Sciences. SAGE Publications, Inc.

Tracey, Paul, and Nelson Phillips. 2007. "The Distinctive Challenge of Educating Social Entrepreneurs." Academy of Management Learning \& Education 6 (2): 264-72. doi:10.5465/AMLE.2007.25223465.

Yin, Robert K. 1994. Case Study Research: Design and Methods. Beverly Hills, CA: SAGE 
Publications Inc. 


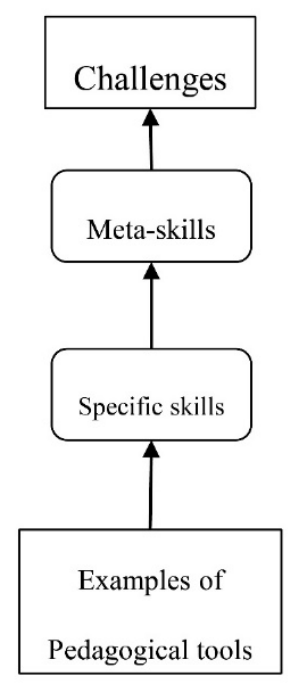

Figure 1. Stages of the paradoxical leadership model for social entrepreneurs developed by (Smith et al. 2012) 
Table 1. Selected social incubators/accelerators and their main characteristics.

\begin{tabular}{|c|c|c|c|}
\hline Organization & $\begin{array}{l}\text { Social incubator/ } \\
\text { accelerator }\end{array}$ & Establishment & Services \\
\hline $\begin{array}{l}\text { Impact Hub } \\
\text { Milano }\end{array}$ & Social incubator & $\begin{array}{l}\text { The hub was established in } \\
\text { 2010. The incubator started } \\
\text { in } 2015 \text {. }\end{array}$ & $\begin{array}{l}\text { SVs co-working space; create } \\
\text { a community for SVs; rent the } \\
\text { space for events; social } \\
\text { incubator and training. }\end{array}$ \\
\hline SocialFare & Social accelerator & $\begin{array}{l}\text { The centre was born in } 2013 . \\
\text { The acceleration programme } \\
\text { started in } 2015 \text {. }\end{array}$ & $\begin{array}{l}\text { Consultancy for SVs; social } \\
\text { accelerator. }\end{array}$ \\
\hline Make a Cube ${ }^{3}$ & Social incubator & 2011. & $\begin{array}{l}\text { Consultancy for SVs; social } \\
\text { incubator. }\end{array}$ \\
\hline
\end{tabular}


Table 2. Selected SVs and their main characteristics.

\begin{tabular}{|c|c|c|c|c|}
\hline Organization & $\begin{array}{l}\text { Being in } \\
\text { social } \\
\text { incubator/ } \\
\text { accelerator }\end{array}$ & $\begin{array}{l}\text { Establishment } \\
\text { of the idea }\end{array}$ & $\begin{array}{l}\text { No. of workers } \\
\text { at the date of } \\
\text { interview }\end{array}$ & Social value \\
\hline $\begin{array}{l}\text { Italia } \\
\text { nonprofit }\end{array}$ & Yes & 2014 & $\begin{array}{l}2 \text { co-founders } \\
\text { and } 2 \\
\text { freelancers. }\end{array}$ & $\begin{array}{l}\text { Access to information about } \\
\text { nonprofit organizations in Italy to } \\
\text { increase the value of donations. }\end{array}$ \\
\hline $\begin{array}{l}\text { Sport Grand } \\
\text { Tour }\end{array}$ & Yes & 2015 & $\begin{array}{l}1 \text { founder, } 2 \\
\text { workers and } 4 \\
\text { freelancers. }\end{array}$ & $\begin{array}{l}\text { Open the space for kids to } \\
\text { discover their talent in the sport } \\
\text { by giving them choices and the } \\
\text { opportunity to try before } \\
\text { officially registering in any } \\
\text { sports club. }\end{array}$ \\
\hline Yeerida & Yes & 2012 & $\begin{array}{l}3 \text { co-founders } \\
\text { and } 3 \text { workers. }\end{array}$ & $\begin{array}{l}\text { Digital library to everyone allows } \\
\text { people read and consult texts; } \\
\text { allows publishers and authors to } \\
\text { promote their work and stay in } \\
\text { touch with their readers. }\end{array}$ \\
\hline Merkur.io & Yes & 2016 & 3 co-founders. & $\begin{array}{l}\text { Secure, fast and scalable payment } \\
\text { network for growing economies } \\
\text { based on blockchain technology. }\end{array}$ \\
\hline Helperbit & No & 2014 & 6 co-founders. & $\begin{array}{l}\text { Transparent, free and secure way } \\
\text { to fundraise based on blockchain } \\
\text { technology. }\end{array}$ \\
\hline Merits & No & 2015 & $\begin{array}{l}2 \text { co-founders } \\
\text { and } 2 \text { workers. }\end{array}$ & $\begin{array}{l}\text { An innovative network to donate } \\
\text { to social organizations using the } \\
\text { digital currency Merits. }\end{array}$ \\
\hline
\end{tabular}


Table 3. Distinctive managerial challenges and their presence under the three managerial dimensions defined by Austen et al. (2006).

Organizational mission Financial resources Human resources

\begin{tabular}{r|ccc}
\hline Risk of mission drift & $\mathrm{X}$ & $\mathrm{X}$ & $\mathrm{X}$ \\
Stakeholders' conflicting demands & $\mathrm{X}$ & $\mathrm{X}$ & $\mathrm{X}$ \\
The need for impact measurement & & $\mathrm{X}$ & $\mathrm{X}$ \\
SV based on new technology & $\mathrm{X}$ & $\mathrm{X}$ & $\mathrm{X}$
\end{tabular}
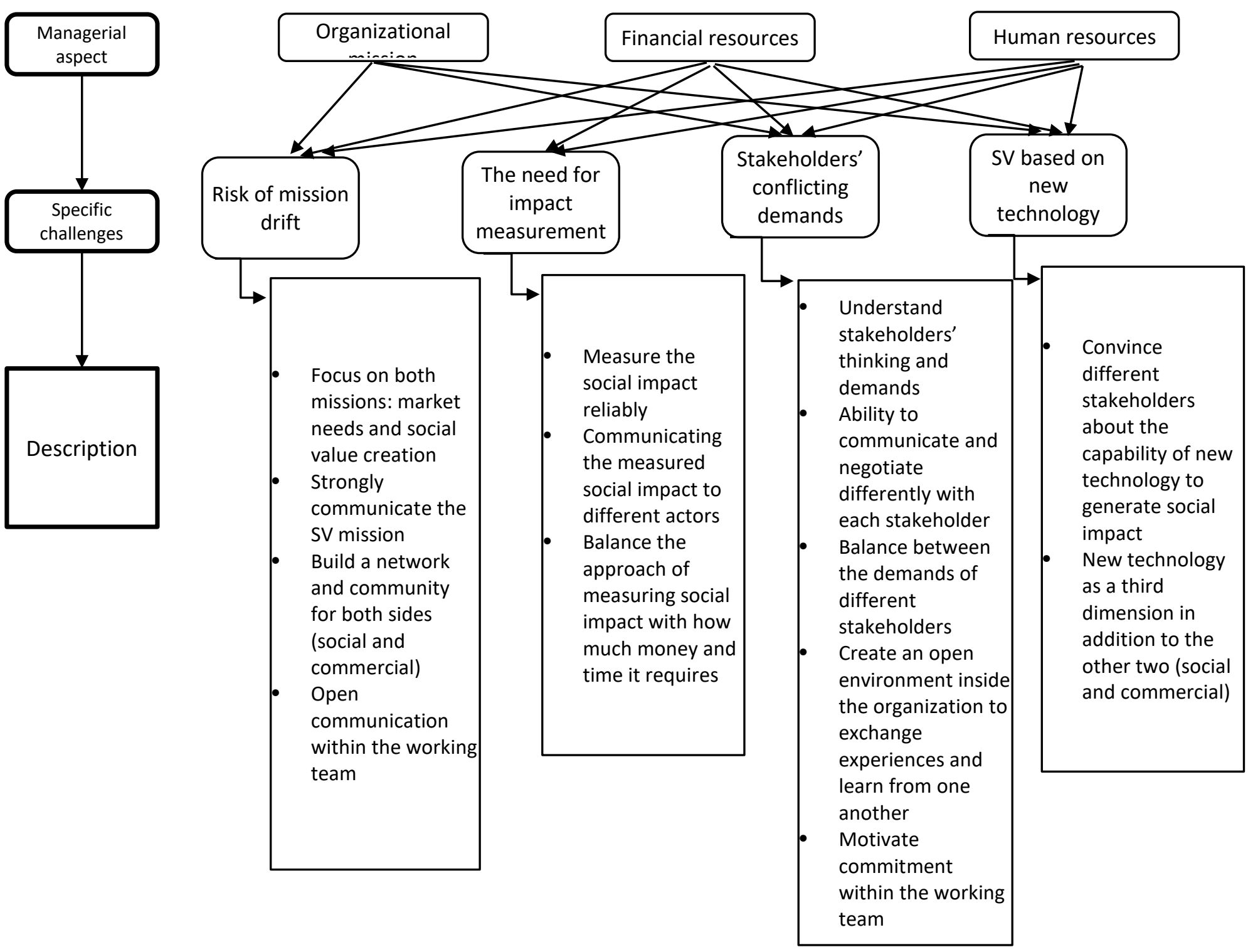
Figure 2. A synthetic analysis of the specific challenges of managing SVs with competing demands 
Table 4. Association of the specific challenges with the suggested specific skills by Smith et al. (2012)

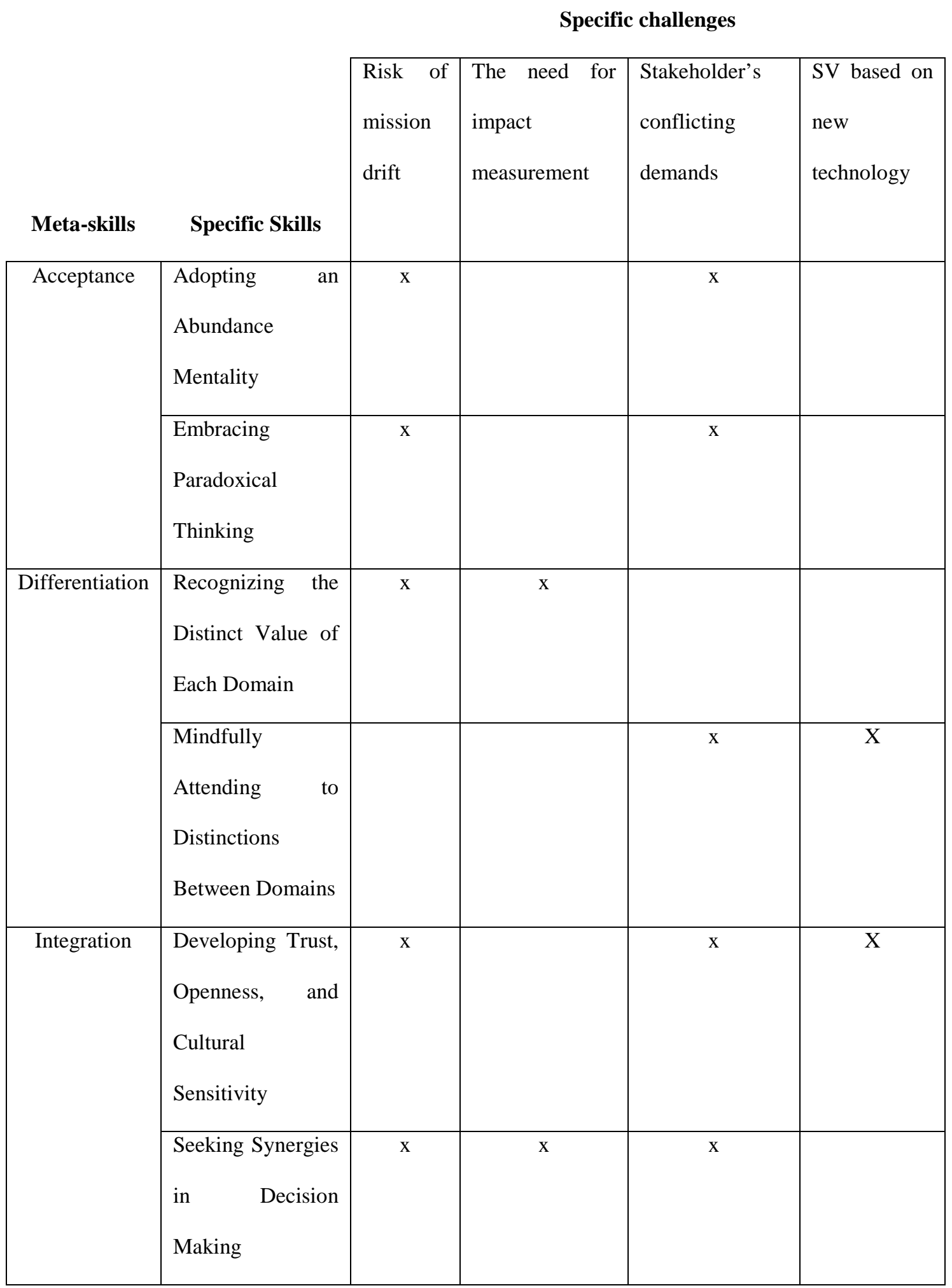

